УДК 334

$10.17213 / 2075-2067-2021-3-230-237$

\title{
ВЛИЯНИЕ ПАНДЕМИИ СОVID-19 НА ДЕЯТЕЛЬНОСТЬ ЭЛЕКТРОННОЙ ТОРГОВОЙ ПЛОЩАДКИ ГАЗПРОМБАНКА: СОСТОЯНИЕ И ПЕРСПЕКТИВЫ РАЗВИТИЯ
}

\author{
(C) 2021 г. Е. И. Титова, Л. В. Голощапова, Н. П. Савина
}

Российский экономический университет имени Г. В. Плеханова, г. Москва, Россия

Цель исследования: изучить основные показатели деятельности электронной торговой площадки ГПБ, оценить влияние пандемии COVID-19 на ее деятельность и предложить пути дальнейшего развития эффективного инструмента организащии закупок ПАО «Газпром».

Материалы, методы и условия проведения исследований. Изучены данные официального сайта электронной торговой площадки ГПБ, а также федеральный закон от 05.04.2013 г. №44-Ф3 «О контрактной системе в сфере закупок товаров, работ, услуг для обеспечения государственныхх и муниципальных нужд» и федеральньй закон от 18.07.2011 г. №223-Ф3 «О закупках товаров, работ, услуг отдельньми видами юридических лицу».

Задачи исследования: проанализировать и оценить влияние пандемии COVID-19 на деятельность электронной торговой площадки ГПБ и предложить пути дальнейтего развития эффективного инструмента организации закупок.

Результаты исследования. В исследовании рассмотрена специфика работы электронной торговой площадки ГПБ: историческая справка создания электронной торговой площадки; оценены особенности ее функиионирования и направления деятельности, основные заказчики и отрасли; проанализировано количество торгов по отраслям по состоянию на конеи 2020 года и влияние пандемии COVID-19 на основные показатели деятельности ЭТП ГПБ.

Перспективы исследования. Тенденции в современной закупочной сфере свидетельствуют о том, что основная часть торгов проводится в электронном формате, что относится и к государственным закупкам, которые в большей части уже переведень в электронные процедуры, а электронная торговая площадка ГПБ является одной из ведущих в данной сфере, поэтому анализ ее деятельности весьма актуален.

Ключевые слова: электронная торговая площадка; направления деятельности; заказчики; торги; количество торгов; аналитика торгов; пандемия COVID-19; организация закупок ПАО «Газпром».

\section{THE IMPACT OF THE COVID-19 PANDEMIC ON THE ACTIVITIES OF THE GAZPROMBANK ELECTRONIC TRADING PLATFORM: STATE AND PROSPECTS OF DEVELOPMENT}

\author{
(C) 2021 E. I. Titova, L. V. Goloshchapova, N. P. Savina
}

\section{Plekhanov Russian University of Economics, Moscow, Russia}

The purpose of the study: to consider the main performance indicators of the GPB electronic trading platform and the impact of the COVID-19 pandemic on its activities. 
Materials, methods and research conditions. The data of the official website of the electronic trading platform of the GPB, as well as Federal Law №44-FZ of 05.04.2013 "On the Contract System in the field of Procurement of goods, works, and services for State and Municipal Needs» and Federal Law №223-FZ of 18.07.2011 «On Procurement of goods, Works, and Services by Certain Types of Legal Entities» were studied.

Research objectives: to analyze and evaluate the impact of the COVID-19 pandemic on the activities of the GPB electronic trading platform.

Research results. The article considers the specifics of electronic trading platform of the GPB: the historical background of the electronic trading platform creation; assesses the features of its functioning and activities, the main customers and industries; analyzes the number of trades by industry as of the end of 2020 and the impact of the COVID-19 pandemic on the main performance indicators of the GPB ETP.

Research perspectives. Trends in the modern procurement sphere indicate that the main part of the bidding is carried out in electronic form. This also applies to public procurement, which for the most part has already been converted to electronic procedures, so the role of electronic trading platforms in procurement is very high. The electronic trading platform of GPB is one of the leading ones in this field, so the analysis of its activities is very relevant.

Key words: electronic trading platform; areas of activity; customers; trades; number of trades4 analytics of trades; COVID-19 pandemic; procurement organization of PJSC Gazprom.

Электронная торговая площадка ГПБ (ЭТП ГПБ) является электронной платформой для закупок, на которой с октября 2018 года стали проводиться торги по 44-Ф3 [7]. Данная площадка была создана в 2012 году для осуществления закупочной деятельности преимущественно корпоративными клиентами Банка и предприятиями группы «Газпром». ЭТП ГПБ входит в перечень электронных торговых площадок, отобранных согласно Распоряжению от 12 июля 2018 года №1447-р [5].

Электронная торговая площадка ГПБ включает в себя две секции: общую секцию для корпоративных клиентов и отдельную для предприятий группы «Газпром». В 2013 году был создан корпоративный интернет-магазин для осуществления малых закупок, не превышающих в сумме 500 тысяч рублей. Это способствовало повышению доступа малых и средних организаций к закупкам крупных монопольных компаний и предприятий с государственным участием [4]. Работа сервиса была построена таким образом, чтобы заказчик мог сравнивать цены и условия в прайслистах поставщиков, выбирая в итоге наиболее подходящего [7].

В 2016 году была запущена аналитическая система TradeInspect с целью обеспече- ния возможности изучить положение поставщика на рынке. Сервис очень удобен с точки зрения получения информации, поскольку нет необходимости обращаться в другие источники для анализа контрагентов - все необходимые документы (выписка из ЕГРЮЛ, сведения об участии компании в арбитражах и исполнительных производствах, финансовые показатели) будут предоставлены.

ЭТП ГПБ имеет высокое качество технической и клиентской поддержки, что позволяет легко планировать проведение закупок и осуществлять контроль над заключенными сделками, есть возможности получения индивидуальной отчетности и анализа больших массивов информации. Возможность определить в одном лоте двух и более победителей позволяет разделить крупный заказ на несколько поставщиков, что является важным преимуществом для малых и средних организаций, которым сложно выиграть крупный тендер. Также на площадке можно комбинировать процедуры в рамках одной закупки. Высокое качество сервиса и минимизация затрат на поиски клиентов и партнеров делают электронную площадку ГПБ конкурентоспособной среди других операторов электронных закупок. 
Организации, которые участвуют в закупках в качестве заказчика с использованием ЭТП ГПБ, представлены в таблице 1.

Оператор электронной торговой площадки ГПБ работает с самыми разными отраслями деятельности, то есть, что касается отраслевой направленности, в целом нет никаких ограничений. Государственные компании, корпорации, государственные заказчики, коммерческие заказчики являются участниками торгов, проводимых на ЭТП ГПБ. Направления, по которым осуществляется деятельность ЭТП ГПБ, представлены в таблице 2. Они обозначены на сайте электронной площадки и включают в себя практически все аспекты закупочной деятельности.

Если проследить аналитику количества торгов со стороны заказчиков на платформе электронной торговой площадки ГПБ, то полученные результаты также можно показать в виде таблицы (табл. 3). В торгах участвуют предприятия разной отраслевой принадлежности. Как видно из таблицы, лидируют заказчики из сферы обрабатывающих производств, которые провели больше всего торгов на данной платформе (в количестве 161577).
Рассмотрим некоторые предприятия, которые участвуют в торгах на ЭТП ГПБ в качестве заказчиков, и представим их в таблице 4.

Таким образом, среди ведущих заказчиков ЭТП ГПБ лидирует ПАО «Газпром» с 38050 торгами.

Рассмотрим, как изменились показатели торгов в 2020 году по сравнению с 2019 годом (таблица 5).

Как видно из таблицы 5, в первом, третьем и четвертом квартале 2020 года наблюдается устойчивый рост количества торгов, проводимых на электронной торговой площадке по сравнению с 2019 годом. Во втором квартале 2020 года ситуация несколько изменилась, что связано с началом пандемии COVID-19 и общим ухудшением экономического положения страны из-за этого. Но, несмотря на пандемию, количество торгов во втором квартале 2020 года по сравнению с соответствующим периодом 2019 года не уменьшилось, а незначительно увеличилось (на $1,62 \%$ ), что говорит о стабильной ситуации. К третьему кварталу 2020 года ситуация улучшилась, наблюдается частичный возврат к показателям первого квартала 2020 года. В четвертом квартале 2020 года

Таблица 1

Заказчики и отрасли, которые представлены на электронной торговой площадке ГПБ [7]

\begin{tabular}{|l|l|}
\hline \multicolumn{1}{|c|}{ Направления деятельности } & \multicolumn{1}{|c|}{ Предприятия-заказчики } \\
\hline Торговля в розничной сфере & М-видео, ДИКСИ, Рив-гош \\
\hline Предприятия агропромышленного комплекса & Мираторг \\
\hline Предприятия микроэлектроники & Концерн РТИ \\
\hline $\begin{array}{l}\text { Организации жилищно-коммунального } \\
\text { хозяйства }\end{array}$ & Росводоканал \\
\hline $\begin{array}{l}\text { Предприятия военно-промышленного } \\
\text { комплекса }\end{array}$ & Военторг \\
\hline Страхование & Согаз \\
\hline Химическая & Уралхим \\
\hline Аэропорты России & Шереметьево, Новапорт аэропорты России \\
\hline Космическая сфера & $\begin{array}{l}\text { НПО Энергомаш, ОАО Российские косми- } \\
\text { ческие системы }\end{array}$ \\
\hline Металлургия & ЧТПЗ \\
\hline Горнодобывающая промышленность & УГМК, Мечел \\
\hline Строительная сфера & Группа ПИК, МРТС, Спецстрой России \\
\hline Машиностроительные предприятия & ОМЗ, Уралмаш, Алмаз-Антей \\
\hline
\end{tabular}


количество торгов выросло и по сравнению с соответствующим периодом 2019 года, и по сравнению с предыдущими кварталами 2020 года. При этом относительно суммы торгов отмечен значительный рост показателя: в первом квартале он вырос на 314,71\%, во втором - на $237,85 \%$, в третьем - на $127,41 \%$, что говорит о значительном росте объемов торгов на площадке.

Аналитика торгов ЭТП ГПБ за период с 2012 по 2020 гг. представлена на рисунке 1.

Согласно представленным на рисунке 1 данным видно, что с 2017 года в целом наблюдается тенденция к ежегодному росту

\section{Направления деятельности ЭТП ГПБ [7]}

Таблица 2

\begin{tabular}{|l|l|}
\hline \multicolumn{1}{|c|}{ Направление } & \multicolumn{1}{|c|}{ Пояснение } \\
\hline Закупки ГК «Газпром» & $\begin{array}{l}\text { Осуществление закупочной деятельности предприятий группы } \\
\text { компаний «Газпром» }\end{array}$ \\
\hline $\begin{array}{l}\text { Закупки корпоративных } \\
\text { заказчиков }\end{array}$ & $\begin{array}{l}\text { Закупки, осуществляемые коммерческими организациями, го- } \\
\text { сударственными корпорациями, либо компаниями, имеющими } \\
\text { в уставном капитале долю, принадлежащую государству }\end{array}$ \\
\hline $\begin{array}{l}\text { Закупки государственных } \\
\text { заказчиков }\end{array}$ & $\begin{array}{l}\text { Закупки согласно 44-ФЗ, 615-ПП РФ. А также торги по услугам } \\
\text { вывоза и утилизации ТКО }\end{array}$ \\
\hline Торговый портал & Закупки через прямой заказ \\
\hline $\begin{array}{l}\text { Аренда и продажа } \\
\text { имущества }\end{array}$ & $\begin{array}{l}\text { Продажа имущества, непрофильных активов, имущества госу- } \\
\text { дарственных организаций (проведение торгов) }\end{array}$ \\
\hline Поддержка поставщиков & $\begin{array}{l}\text { Оказание консультационных услуг при регистрации и работе на } \\
\text { ЭТП ГПБ }\end{array}$ \\
\hline Финансовые сервисы & $\begin{array}{l}\text { Банковские гарантии, кредит на исполнение контракта и другие } \\
\text { финансовые услуги, необходимые в процессе торгов }\end{array}$ \\
\hline $\begin{array}{l}\text { Получение электронной } \\
\text { подписи }\end{array}$ & $\begin{array}{l}\text { Оформление электронной подписи для работы на электронных } \\
\text { торговых площадках }\end{array}$ \\
\hline Аналитика закупок & $\begin{array}{l}\text { Использование данных информационно-аналитической систе- } \\
\text { мы ТтадеІплрест для повышения эффективности в закупочном } \\
\text { процессе }\end{array}$ \\
\hline
\end{tabular}

\section{Количество торгов на ЭПТ ГПБ со стороны заказчиков по отраслям по состоянию на конец 2020 года [7]}

\begin{tabular}{|l|c|}
\hline \multicolumn{1}{|c|}{ Отрасль } & Количество торгов \\
\hline Строительство & 16188 \\
\hline Обрабатывающие производства & 161577 \\
\hline Торговля и ремонт & 9697 \\
\hline Транспорт и связь & 6871 \\
\hline Недвижимость & 5083 \\
\hline Добыча полезных ископаемых & 4911 \\
\hline Финансы & 1029 \\
\hline Другие направления & 47311 \\
\hline
\end{tabular}


и количества проведенных торгов, и их суммы в денежном выражении. 2020 год начался весьма успешно. Некоторый спад количества торгов наблюдается во втором квартале 2020 года, что связано с пандемией коронавиpyca. Но, несмотря на COVID-19, показатели деятельности электронной торговой площад- ки ГПБ за четвертый квартал 2020 года достигли своего максимума, превысив по количеству и сумме торгов результаты за предыдущие кварталы, начиная с третьего квартала 2012 года [6].

В заключение можно сделать следующие выводы.

Таблица 4

\section{Ведущие заказчики ЭТП ГПБ по состоянию на конец 2020 года [7]}

\begin{tabular}{|l|c|}
\hline \multicolumn{1}{|c|}{ Заказчик } & Количество торгов \\
\hline ПАО «Газпром» & 38050 \\
\hline ГазЭнергоИнформ & 13761 \\
\hline Департамент Госзаказа ЯНАО & 9986 \\
\hline ООО «Газпром центрремонт» & 8428 \\
\hline Востокгазпром & 8291 \\
\hline АО «Газпром закупки» & 6386 \\
\hline ИЗ-Картэкс имени П. Г. Коробкова & 6309 \\
\hline Авиапредприятие «Газпром АВИА» & 6136 \\
\hline Фонд «Газпромипотека» & 5738 \\
\hline ПАО «Уралмашзавод» & 5348 \\
\hline ПАО «Криогенмаш» & 4823 \\
\hline ГазАртСтрой & 4018 \\
\hline Газпром Трансгаз Екатеринбург & 3113 \\
\hline АО РКЦ «Прогресс» & 2298 \\
\hline АО МАШ & 2167 \\
\hline АО «Военторг-центр» & 2077 \\
\hline АО «Авиакомпания «Россия» & 2016 \\
\hline ПАО «Южный Кузбасс» & 1886 \\
\hline Администрация г. Дзержинска & 1581 \\
\hline
\end{tabular}

Таблица 5

Динамика количества и суммы торгов на площадке ЭТП ГПБ за период 2019-2020 гг. [7]

\begin{tabular}{|c|c|c|c|c|c|c|}
\hline $\begin{array}{c}\text { Период } \\
2019-2020 \text { гг. }\end{array}$ & $\begin{array}{c}\text { Количество } \\
\text { торгов, } \\
2019 \text { г. }\end{array}$ & $\begin{array}{c}\text { Количество } \\
\text { торгов, } \\
2020 \text { г. }\end{array}$ & $\begin{array}{c}\text { Изменение } \\
\text { количества } \\
\text { торгов } \\
(2020 \text { г. } \\
\text { к 2019 г.), \% }\end{array}$ & $\begin{array}{c}\text { Сумма } \\
\text { торгов, } \\
2019 \text { г., }\end{array}$ & $\begin{array}{c}\text { Сумма } \\
\text { торгов, } \\
2020 \text { г., } \\
\text { млрд. руб., }\end{array}$ & $\begin{array}{c}\text { Изменение } \\
\text { суммы } \\
\text { торго } \\
(2020 \text { г. } \\
\text { к 2019 г.), \% }\end{array}$ \\
\hline 1 квартал & 21574 & 34969 & $+62,09$ & 221,62455 & 919,09586 & $+314,71$ \\
\hline 2 квартал & 27528 & 27975 & $+1,62$ & 291,75359 & 985,68426 & $+237,85$ \\
\hline 3 квартал & 27821 & 33413 & $+20,10$ & 350,2171 & 796,43944 & $+127,41$ \\
\hline 4 квартал & 37869 & 44664 & $+17,94$ & 868,46025 & 1069,21802 & $+23,12$ \\
\hline
\end{tabular}




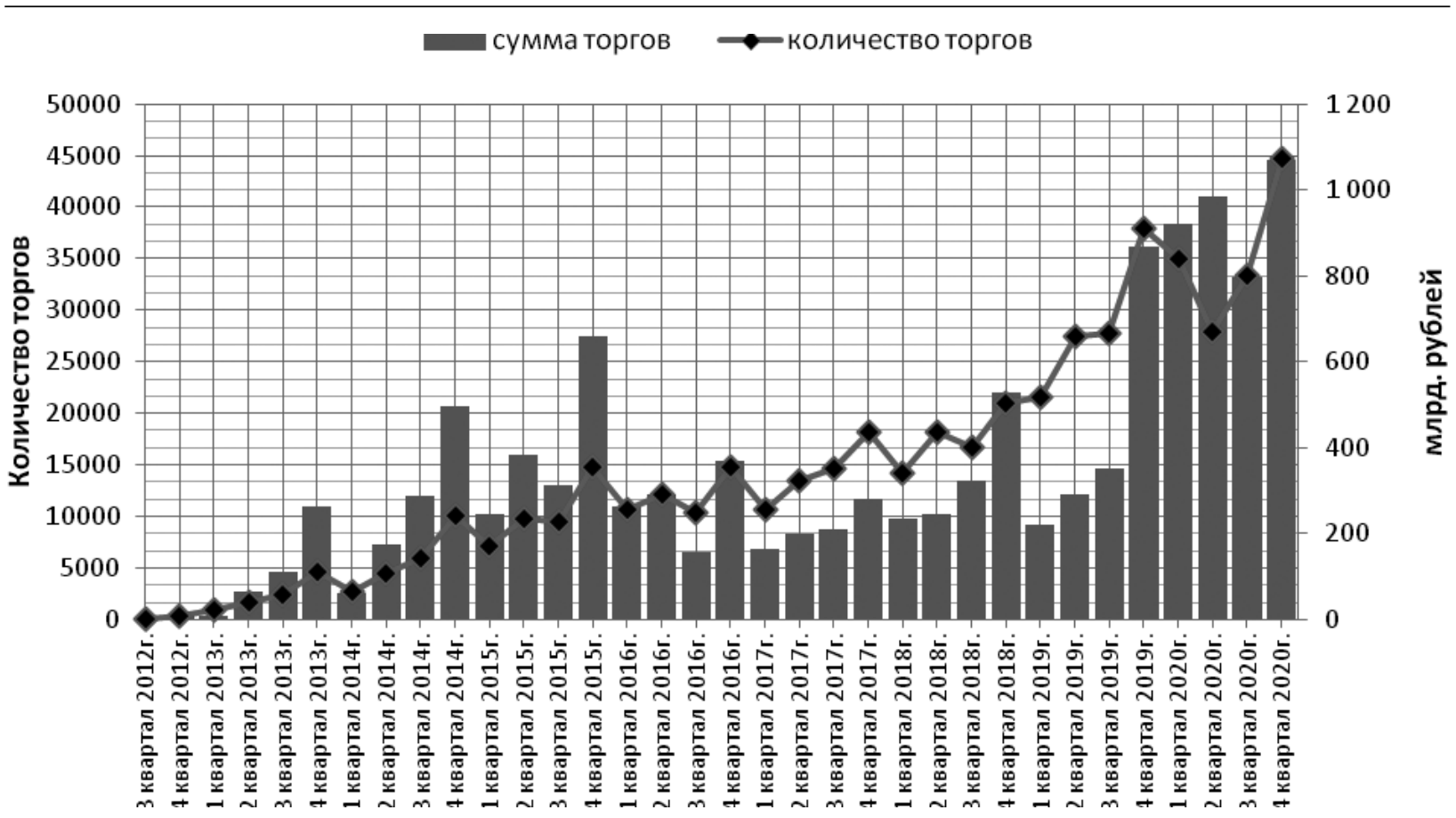

Рис. 1. Аналитика торгов ЭТП ГПБ за период с 2012 по 2020 гг. [7]

Во-первых, работа электронной торговой площадки ГПБ постоянно совершенствуется, на это направлена деятельность экспертов ГПБ, которые активно участвуют в дискуссиях в прессе, в разнообразных совещаниях и конференциях, где высказываются мнения относительно развития процедур по проведению электронных торгов.

Во-вторых, активно ведется разработка системы по оптимизации процесса выбора поставщиков в оптовой сфере для российских организаций, предприятий и предпринимателей. Кроме того, Национальное рейтинговое агентство осуществило разработку методики расчета индексов рынка, касающихся электронных торговых площадок, проводящих торги объемом более ста миллиардов рублей в год, специально для ЭТП ГПБ.

В-третьих, несмотря на то, что в связи с пандемией COVID-192020-й год был непростым для экономического положения страны в целом, на показателях деятельности электронной торговой площадки это отразилось в незначительной мере. Только во втором квартале 2020 года наблюдается небольшой спад по количеству и сумме торгов на площадке. К концу 2020 года ситуация значительно улучшилась, достигнув своего максимума за весь период деятельности.

\section{Литература}

1. О контрактной системе в сфере закупок товаров, работ, услуг для обеспечения государственных и муниципальных нужд: Федеральный закон от 05.04.2013 г. №44-Ф3 (в ред. от 31.07.2020 г.) [Электронный ресурс]/ СПС «Гарант». - Режим доступа: https://base. garant.ru.

2. О закупках товаров, работ, услуг отдельными видами юридических лиц: Федеральный закон от 18 июля 2011 г. №223-Ф3 (с изменениями и дополнениями) [Электронный ресурс] / СПС «Гарант». - Режим доступа: https://base.garant.ru.

3. О защите конкуренции: Федеральный закон от 26 июля 2006 г. №135-Ф3 (с изменениями и дополнениями) [Электронный pecypc] / СПС «Гарант». - Режим доступа: https://base.garant.ru.

4. Подбиралина Г.В., Мигалева Т.Е. Малый и средний бизнес зарубежных стран и России. Учебник / Cер. Бакалавриат и магистратура. - М.: Издательство «КноРус», 2021. - $202 \mathrm{c}$.

5. Распоряжение Правительства РФ от 12 июля 2018 г. №1447-р Об утверждении Перечня операторов электронных площадок, предусмотренного частью 3 статьи 24.1 Феде- 
рального закона от 5 апреля 2013 г. №44-Ф3, частью 11 статьи 3.4 Федерального закона от 18 июля 2011 г. №223-Ф3 и Перечня операторов специализированных электронных площадок, предусмотренного частью 3 статьи 24.1 Федерального закона от 5 апреля 2013 г. №4-Ф3, операторов электронных площадок для осуществления закрытых конкурентных закупок, предусмотренный частью 4 статьи 3.5 Федерального закона от 18 июля 2011 г. №223-Ф3 [Электронный ресурс] / СПС «Гарант». - Режим доступа: https://www. garant.ru.

6. Аналитика закупок ЭТП ГПБ [Электронный ресурс] // Электронная торговая площадка ГПБ. — Режим доступа: https://etpgpb.ru.

7. ЭТП ГПБ Электронная торговая площадка Группа Газпромбанка [Электронный pecypc]. - Режим доступа: https://etpgpb.ru.

\section{References}

1. O kontraktnoj sisteme v sfere zakupok tovarov, rabot, uslug dlja obespechenija gosudarstvennyh i municipal'nyh nuzhd: Federal'nyj zakon ot 05.04.2013 g. №44-FZ ( $v$ red. ot 31.07 .2020 g.) [On the contract system in the field of procurement of goods, works, and services for State and Municipal Needs: Federal Law №44-FZ of 05.04.2013 (as amended from 31.07.2020)] [Jelektronnyj resurs] / SPS «Garant». - URL: https://base.garant.ru.

2. O zakupkah tovarov, rabot, uslug otdel'nymi vidami juridicheskih lic: Federal'nyj zakon ot 18 ijulja 2011 g. №223-FZ (s izmenenijami i dopolnenijami) [On purchases of goods, works, and services by certain types of legal entities: Federal Law №223-FZ of July 18, 2011 (with amendments and additions)] [Jelektronnyj resurs]/ SPS «Garant». — URL: https:// base.garant.ru.

3. O zashhite konkurencii: Federal'nyj zakon ot 26 ijulja 2006 g. №135-FZ (s izmenenijami i dopolnenijami) [On Protection of competition: Federal Law №135-FZ of July 26, 2006 (with amendments and additions)] [Jelektron- nyj resurs]/ SPS «Garant». — URL: https:// base.garant.ru.

4. Podbiralina G.V., Migaleva T.E. Malyj i srednij biznes zarubezhnyh stran i Rossii. Uchebnik [Small and medium business of foreign countries and Russia. Textbook] / Ser. Bakalavriat i magistratura [Ser. Bachelor's and Master's Degrees]. — Moscow: Izdatel'stvo «KnoRus», 2021. - 202 p.

5. Rasporjazhenie Pravitel'stva RF ot 12 ijulja 2018 g. №1447-r Ob utverzhdenii Perechnja operatorov jelektronnyh ploshhadok, predusmotrennogo chast'ju 3 stat'i 24.1 Federal'nogo zakona ot 5 aprelja 2013 g. №44-FZ, chast'ju 11 stat'i 3.4 Federal'nogo zakona ot 18 ijulja 2011 g. №223-FZ i Perechnja operatorov specializirovannyh jelektronnyh ploshhadok, predusmotrennogo chast'ju 3 stat'i 24.1 Federal'nogo zakona ot 5 aprelja 2013 g. №4-FZ, operatorov jelektronnyh ploshhadok dlja osushhestvlenija zakrytyh konkurentnyh zakupok, predusmotrennyj chast'ju 4 stat'i 3.5 Federal'nogo zakona ot 18 ijulja 2011 g. №223-FZ [Order of the Government of the Russian Federation №1447-r of July 12, 2018 On Approval of the List of Operators of Electronic Platforms Provided for in Part 3 of Article 24.1 of Federal Law №44-FZ of April 5, 2013, Part 11 of Article 3.4 of Federal Law №223-FZ of July 18, 2011, and the List of Operators of Specialized Electronic Platforms Provided for in Part 3 of Article 24.1 of Federal Law №4-FZ of April 5, 2013, Operators of electronic Platforms for Closed Competitive Procurement provided for in Part 4 of Article 3.5 of Federal Law №18, 2011. №223-FZ] [Jelektronnyj resurs] / SPS «Garant». — URL: https:// www.garant.ru.

6. Analitika zakupok JeTP GPB [Analytics of procurement of ETP GPB] [Jelektronnyj resurs] // Jelektronnaja torgovaja ploshhadka GPB [Electronic trading platform GPB]. URL: https://etpgpb.ru.

7. JeTP GPB Jelektronnaja torgovaja ploshhadka Gruppa Gazprombanka [ETP GPB Electronic trading platform Gazprombank Group] [Jelektronnyj resurs]. — URL: https://etpgpb.ru. 

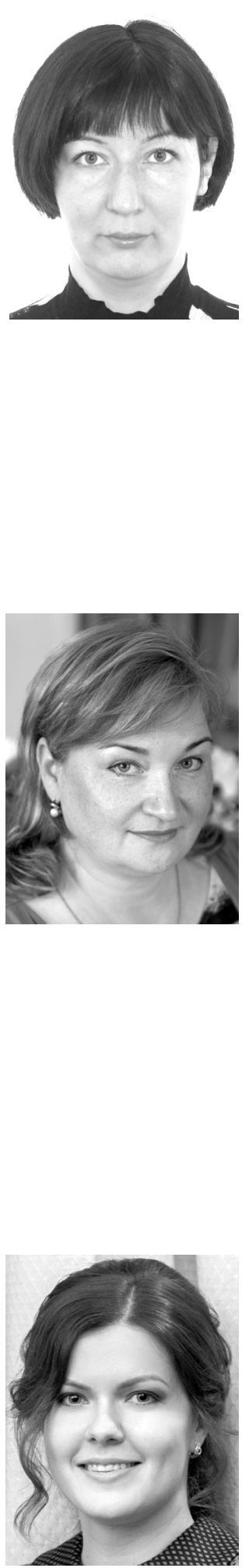

Титова Екатерина Игоревна - студентка 1 курса магистратуры базовой кафедры финансового контроля, анализа и аудита Главного контрольного управления города Москвы Российского экономического университета имени Г. В. Плеханова.

Titova Ekaterina Igorevna - 1st year magistracy student of the Basic Department of Financial control, Analysis and Audit of the Main Control Department of Moscow, Plekhanov Russian University of Economics.

117997, г. Москва, Стремянный пер., 36

36 Stremyanny $\ln ., 117997$, Moscow, Russia

E-mail: cool.lvg2012@yandex.ru

Голощапова Людмила Вячеславовна - кандидат экономических наук, доцент базовой кафедры финансового контроля, анализа и аудита Главного контрольного управления города Москвы Российского экономического университета имени Г.В. Плеханова.

Goloshchapova Liudmila Vyacheslavovna - Candidate of Economic Sciences, Associate Professor of the Basic Department of Financial control, Analysis and Audit of the Main Control Department of Moscow, Plekhanov Russian University of Economics.

117997, г. Москва, Стремянный пер., 36

36 Stremyanny ln., 117997, Moscow, Russia

E-mail: cool.lvg2012@yandex.ru

Савина Наталья Павловна - кандидат экономических наук, доцент кафедры мировой экономики Российского экономического университета имени Г.В. Плеханова.

Savina Natalia Pavlovna - Candidate of Economic Sciences, Associate professor of World Economy Department, Plekhanov Russian University of Economics.

117997, г. Москва, Стремянный пер., 36

36 Stremyanny ln., 117997, Moscow, Russia

E-mail: Savina.NP@rea.ru 